\title{
Diagnóstico e técnicas de correção do sorriso gengival
}

\author{
Gummy smile diagnosis and correction techniques \\ Técnicas de diagnóstico y corrección de la sonrisa gingival
}

Recebido: 22/01/2022 | Revisado: 29/01/2022 | Aceito: 30/01/2022 | Publicado: 31/01/2022

\author{
Laís Christina Pontes Espíndola \\ ORCID: https://orcid.org/0000-0002-1023-7891 \\ Universidade Federal de Alagoas, Brasil \\ E-mail: laisespindola@hotmail.com \\ Dyana dos Santos Fagundes \\ ORCID: https://orcid.org/0000-0002-7427-4114 \\ Universidade Federal de Alagoas, Brasil \\ E-mail: dydyana_fagundes@hotmail.com \\ Vinícius Hallan Souza de Lima \\ ORCID: https://orcid.org/0000-0002-2711-744X \\ Universidade Federal de Alagoas, Brasil \\ E-mail: viniciushallan@hotmail.com \\ Willames Rafael de Jesus Cavalcante \\ ORCID: https://orcid.org/0000-0002-1552-1189 \\ Universidade Federal de Uberlândia, Brasil \\ E-mail: drwillamescavalcante@gmail.com \\ Thalwylla Reiler Morato dos Reis Moreira \\ ORCID: https://orcid.org/0000-0001-5632-2322 \\ Universidade Federal de Alagoas, Brasil \\ E-mail: thalwyllamorato@yahoo.com.br
}

\begin{abstract}
Resumo
O termo sorriso gengival é caracterizado pela exposição excessiva de tecido gengival ao sorrir, sendo uma condição estética relativamente frequente, que gera insatisfação e umas das maiores queixas estéticas em relação ao sorriso. Um diagnóstico correto e preciso, requer a avaliação dos tecidos moles e ósseos da face, seguidos por uma avaliação intraoral dos dentes/ tecido gengival e sua relação com os lábios. Exames imagiológicos podem ser essenciais para auxiliar o profissional no diagnóstico. Para que o tratamento do sorriso gengival seja realizado, é indispensável que o Cirurgião-Dentista conheça e entenda todas as etiologias inerentes e compreenda que múltiplos fatores podem estar presentes simultaneamente, e assim, selecionar a técnica mais pertinente ao caso. Etiologias multifatoriais podem exigir múltiplas modalidades de tratamentos para que se alcance um resultado satisfatório. Os métodos de tratamento incluem diversas técnicas como gengivoplastias, ressecção ósseas, técnicas para reduzir a elevação do lábio superior, abordagens maxilofaciais e terapias ortodônticas. A finalidade dessa pesquisa científica é abordar os métodos de diagnóstico e as diferentes técnicas de correção gengival descritas na literatura por meio de uma revisão de literatura. Buscas nas bases de dados Scientific Eletronic Library Online (SciELO), Biblioteca Virtual em Saúde (BVS), US National library of Medicine National Institutes of Health (PubMed) e Google Acadêmico foram feitas. Pode-se concluir que um diagnóstico correto é essencial para delinear um planejamento preciso no tratamento e ofertar ao paciente um tratamento individualizado, com resultados satisfatórios a longo prazo e que atendam suas expectativas do ponto de vista estético e funcional.
\end{abstract}

Palavras-chave: Estética dentária; Sorriso; Gengiva.

\begin{abstract}
The term gummy smile is characterized by the excessive exposure of gingival tissue when smiling, being a relatively frequent aesthetic condition, which generates dissatisfaction and one of the biggest aesthetic complaints regarding the smile. A correct and accurate diagnosis requires assessment of the soft and bony tissues of the face, followed by an intraoral assessment of the teeth/gingival tissue and their relationship to the lips. Imaging exams can be essential to help the professional in the diagnosis. For the treatment of gummy smile to be carried out, it is essential that the Dental Surgeon knows and understands all the inherent etiologies and understands that multiple factors can be present simultaneously, and thus, select the most pertinent technique to the case. Multifactorial etiologies may require multiple treatment modalities to achieve a satisfactory result. Treatment methods include various techniques such as gingivoplasty, bone resection, techniques to reduce upper lip elevation, maxillofacial approaches, and orthodontic therapies. The purpose of this scientific research is to approach the diagnostic methods and the different techniques of gingival correction described in the literature through a literature review. Searches in the Scientific Electronic Library Online (SciELO), Virtual Health Library (BVS), US National library of Medicine National Institutes of Health
\end{abstract}


(PubMed) and Google Scholar databases were performed. It can be concluded that a correct diagnosis is essential to outline an accurate treatment plan and offer the patient an individualized treatment, with satisfactory long-term results and that meet their expectations from an aesthetic and functional point of view.

Keywords: Dental aesthetics; Smile; Gingiva.

\begin{abstract}
Resumen
El término sonrisa gingival se caracteriza por la excesiva exposición del tejido gingival al sonreír, siendo una condición estética relativamente frecuente, que genera insatisfacción y una de las mayores quejas estéticas respecto a la sonrisa. Un diagnóstico correcto y preciso requiere una evaluación de los tejidos blandos y óseos de la cara, seguida de una evaluación intraoral de los dientes/tejido gingival y su relación con los labios. Los exámenes de imagen pueden ser fundamentales para ayudar al profesional en el diagnóstico. Para que el tratamiento de la sonrisa gingival se lleve a cabo es fundamental que el Cirujano Dentista conozca y comprenda todas las etiologías inherentes y entienda que múltiples factores pueden estar presentes simultáneamente, y así seleccionar la técnica más pertinente al caso. Las etiologías multifactoriales pueden requerir múltiples modalidades de tratamiento para lograr un resultado satisfactorio. Los métodos de tratamiento incluyen diversas técnicas como la gingivoplastia, la resección ósea, técnicas para reducir la elevación del labio superior, abordajes maxilofaciales y terapias de ortodoncia. El propósito de esta investigación científica es acercarnos a los métodos diagnósticos y las diferentes técnicas de corrección gingival descritas en la literatura a través de una revisión bibliográfica. Se realizaron búsquedas en las bases de datos Scientific Electronic Library Online (SciELO), Virtual Health Library (BVS), US National Library of Medicine National Institutes of Health (PubMed) y Google Scholar. Se puede concluir que un correcto diagnóstico es fundamental para trazar un plan de tratamiento acertado y ofrecer al paciente un tratamiento individualizado, con resultados satisfactorios a largo plazo y que cubran sus expectativas desde el punto de vista estético y funcional.
\end{abstract}

Palabras clave: Estética dental; Sonrisa; Encía.

\title{
1. Introdução
}

O sorriso é considerado um padrão de beleza e bem-estar, uma importante expressão facial que revela um estado de satisfação, alegria, sucesso, bondade e confiança, designada como uma “primeira impressão". Um sorriso representa, além de uma forma de comunicação, um meio de socialização. Um sorriso atrativo depende não só do tamanho, cor e alinhamento dos dentes no arco, mas também da quantidade de gengiva exposta e da relação dos mesmo com os lábios (Oliveira et al., 2013; Cairo et al., 2012; Galdino et al., 2021; Silva et al., 2021; Espíndola et al., 2021).

Diversos parâmetros são adotados na literatura para classificar o sorriso gengival de acordo com a quantidade em milímetros de gengiva exposta, alguns autores sugeriram uma padronização nessa medida; Garber e Salama, (1996) e diversos outros autores caracterizam sorriso gengival como uma exposição maior ou igual a $3 \mathrm{~mm}$.

Já Chacón Martínez e colaboradores (2011) propuseram uma classificação do sorriso gengival, baseados em 3 níveis de graduação, levando em consideração a severidade na exposição gengival. Sendo o grau I (leve), com exposição da gengiva de 2 a 4 mm; no grau II (moderado), 4 a 6 mm do tecido gengival exposto; e no grau III (grave), um grau de exposição maior que $6 \mathrm{~mm}$.

A etiologia da exposição gengival excessiva pode ser decorrente de alterações diversas, como as de origens esqueléticas, dentárias, labiais, periodontais ou externas. Podendo essa condição surgir como resultado de um fator etiológico isolado ou pela combinação de fatores (Bidra et al., 2012; Espíndola et al., 2021). Portanto, faz-se fundamental o papel do Cirurgião-dentista sobre esta temática, sendo necessário que o mesmo esteja habilitado e conheça as características etiológicas que originam o sorriso gengival, bem como tenha conhecimento para obter diagnóstico preciso para cada caso clínico (Robbins, 1999; Espíndola et al., 2021). Portanto, o presente trabalho tem como finalidade por meio de uma revisão literária abordar o diagnóstico, bem como as formas de técnicas corretivas da exposição gengival excessiva.

\section{Metodologia}

Foi realizada uma pesquisa explanatória descritiva para realização desse estudo de revisão literária em que pesquisa nas seguintes bases de dados: Scientific Eletronic Library Online (SciELO), Biblioteca Virtual em Saúde (BVS), US National 
library of Medicine National Institutes of Health (PubMed), E Google Acadêmico, assim como artigos científicos em bases de dados de instituições de ensino superior no Brasil, e revistas científicas. Os artigos em português e inglês publicados entre os anos de 1996 a 2021 foram selecionados, levando-se em consideração como como critérios de busca as seguintes palavraschave: sorriso; gengiva; estética dentária; sorriso gengival.

\section{Revisão de Literatura}

A perfeita união da dentição, tecido gengival e lábios compõem um sorriso em harmonia. Quando essas estruturas encontram-se na proporção ideal, um sorriso harmônico é estabelecido. Entretanto, em algumas situações esses componentes podem encontrar-se em desequilíbrio, como é visto nos casos de sorriso gengival, considerado um quadro antiestético e desarmônico. Na construção de um sorriso harmônico a área periodontal exerce uma importante função, pois para boa parte das pessoas possuir dentes hígidos, sem cáries, com uma boa coloração, acaba se tornando irrelevante quando presente uma exposição gengival excessiva (Pedron, 2016; Silva et al., 2021; Espíndola et al., 2021). Caracteriza-se como sorriso gengival uma exposição de $3 \mathrm{~mm}$ ou mais de acordo com a literatura (Garber \& Salama, 1996). A severidade no grau de exposição também pode ser classificada, sendo o grau I, considerado uma exposição leve com exposição da gengiva entre 2 a 4 mm; grau II, uma exposição moderada, de 4 a 6 mm do tecido gengival exposto; já no grau III, uma exposição gengival grave, com mais de 6 mm de exposição gengival (Chacón Martínez et al., 2011).

\subsection{Diagnóstico}

Para se obter um diagnóstico adequado, uma série de exames relacionados aos tecidos moles e ósseos da estrutura facial são necessários, além de uma avaliação precisa da cavidade oral, em que as estruturas dentárias, gengivais, relacionadas com a posição labial também são vistas (Panossian, \& Block, 2010). Diversos parâmetros são analisados, como a avaliação da face, onde o comprimento facial é avaliado, medição labial superior, bem como a exposição dos dentes em estado de repouso e em atividade, avaliando dessa forma a elevação labial superior quando a ato de sorrir é feita. Mensuração da harmonia dos arcos dentários, da proporção altura/ largura dos incisivos centrais superiores e avaliação dos tecidos periodontais também são realizadas no exame da cavidade oral (Silberberg et al., 2009).

Todas essas avaliações dos parâmetros acima citadas, vão permitir ao Cirurgião-dentista a obtenção de um diagnóstico preciso, estabelecendo dessa forma um planejamento do tratamento adequado, em que a melhor terapêutica para cada caso é avaliada e dessa forma, obtido um resultado satisfatório aos indivíduos com de sorriso gengival.

\subsubsection{Comprimento facial}

A face é analisada dividindo-a verticalmente em três partes de comprimentos iguais: o terço superior, localizado entre a linha capilar a linha das sobrancelhas; o terço médio, compreendido da linha das sobrancelhas até a linha subnasal; e o terço inferior, circunscrito entre a linha subnasal e o mento (Costa et al., 2004). O terço inferior pode ainda ser dividido em três partes: o terço superior, que vai do ponto subnasal ( $\mathrm{Sn}$ ) até o ponto stômio (borda inferior labial superior, St); e os outros $2 / 3$ inferiores que vão do stômio até o mento (Panossian \& Block, 2010).

Avaliando o terço facial inferior, seu comprimento maior que o dos outros terços, pode indicar uma anormalidade esquelética, causada pelo crescimento excessivo maxilar no sentido vertical. Essa anomalia faz com que a mandíbula gire, aumentando a altura facial vertical e afetando as relações dento-labiais (Figura 1). É indicado uma análise da radiografia cefalométrica lateral quando houver suspeita da discrepância esquelética, avaliando se as dimensões esqueléticas estão dentro do intervalo adequado, confirmando o diagnóstico clínico (Panossian \& Block, 2010). 
Figura 1. Análise da face dividindo-a em três partes: terço superior, terço médio e terço inferior. Nota-se que o paciente apresenta os outros terços maiores em relação ao terço inferior facial.

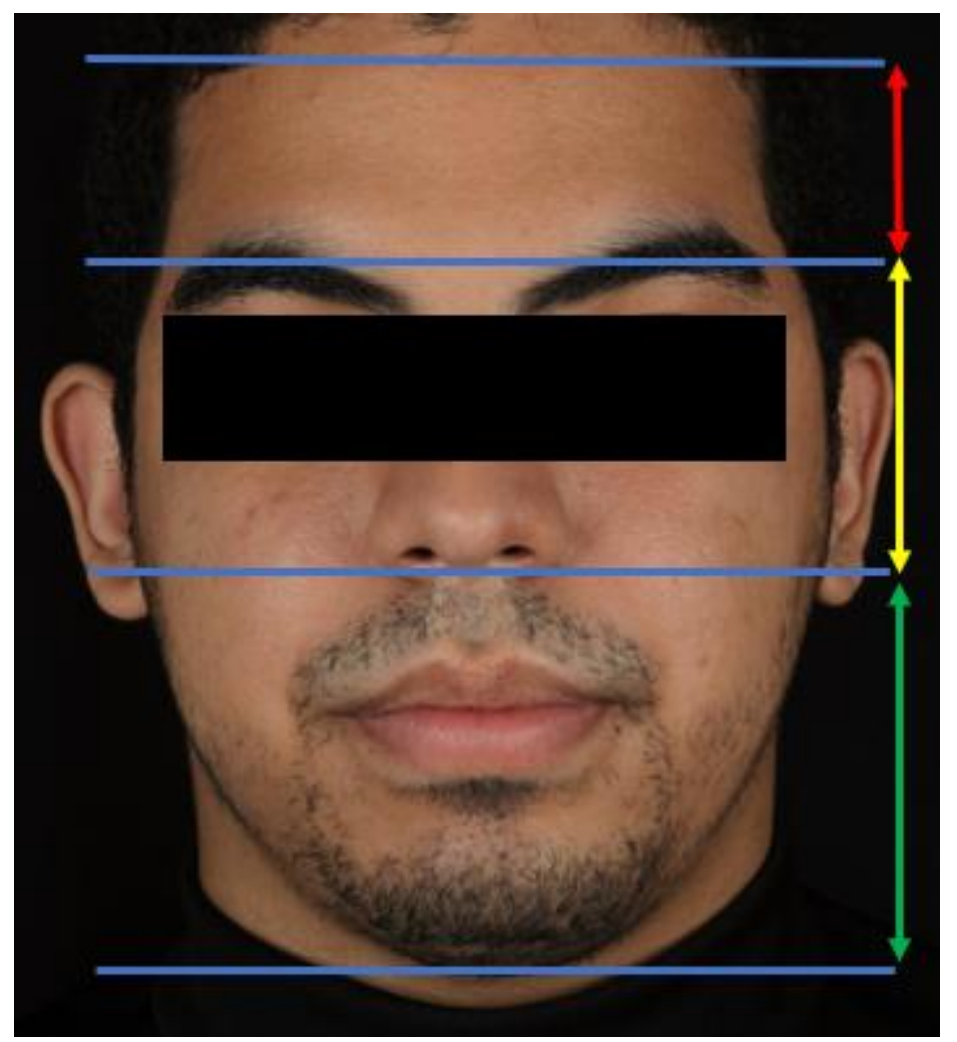

Fonte: Autoria própria.

\subsubsection{Comprimento labial superior}

Do ponto subnasal até o ponto stômio é estabelecido a medida do comprimento labial superior em repouso. A altura normal do lábio superior é de aproximadamente 20-24 mm em adultos jovens, mas tende a diminuir com a idade (Silberberg et al., 2009). Apesar de parecer que indivíduos com lábio superior curto tendem a expor mais tecido gengival ao sorrir, o comprimento labial não tende a ter relação direta com a exposição excessiva gengival, exceto nas situações em que o crescimento excessivo vertical do maxilar faz-se presente (Sabri, 2005).

A relação labial superior com as comissuras labiais é muito significativa durante análise facial: o comprimento do lábio deve ser igual à altura das comissuras. Um lábio com comprimento menor que a altura das comissuras indica um repouso invertido (Figura 2). Em adolescentes pode ser comum encontrar o lábio superior curto nessa relação, devido ao alongamento labial continuar após o crescimento esquelético vertical completar-se (Sabri, 2005; Seixas et al., 2011). 
Figura 2. Relação labial superior e a altura das comissuras labiais: Esquema A: Mostra um lábio superior com comprimento igual à altura das comissuras labiais $\left(\mathrm{C}^{\prime}{ }^{\prime}-\mathrm{C}^{\prime}{ }^{\prime}=\mathrm{Sn}-\mathrm{St}=\mathrm{C} 2^{\prime}-\mathrm{C} 2\right)$. Esquema B: comprimento do lábio menor que a altura das comissuras (Repouso invertido) ( $\mathrm{Sn}-\mathrm{St}<\mathrm{C} 1{ }^{\prime}-\mathrm{C} 1^{\prime}$; $\left.\mathrm{Sn}-\mathrm{St}<\mathrm{C} 2{ }^{\prime}-\mathrm{C} 1^{\prime}\right)$.

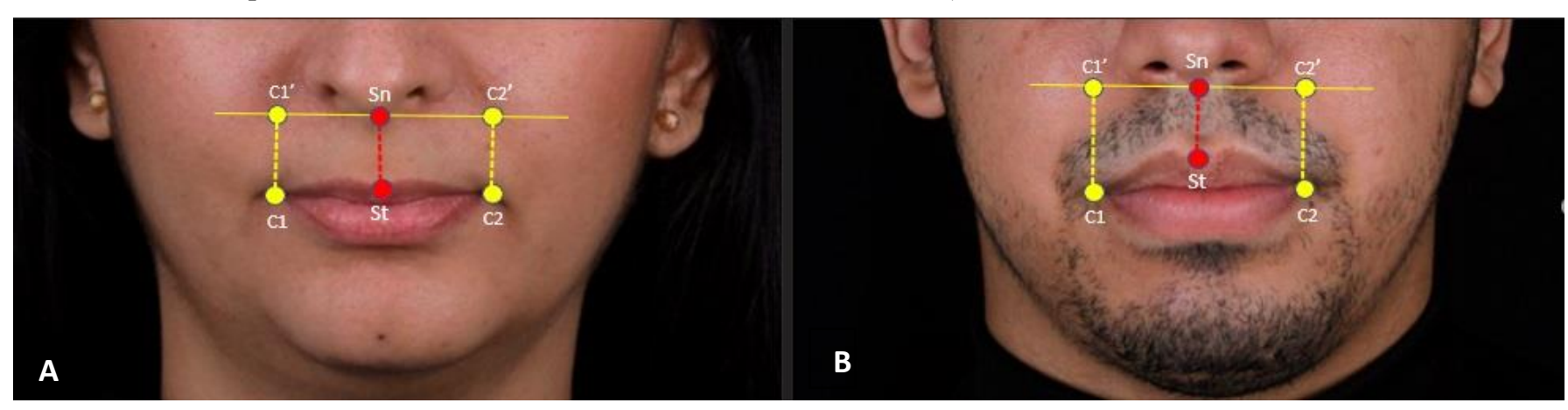

Fonte: Autoria própria.

\subsubsection{Elevação do lábio superior ao sorrir}

Ao sorrir, $80 \%$ do comprimento original do lábio superior é elevado, expondo, aproximadamente, $10 \mathrm{~mm}$ dos incisivos superiores, ou seja, a coroa clínica inteira. Nas mulheres, a elevação dos lábios apresenta-se maiores que nos homens, sendo 3,5\% maior essa elevação (Sabri, 2005). O lábio superior não-hiperativo se desloca de 6 a 8 mm da posição estática para um sorriso amplo, enquanto no lábio superior hiperativo uma distância de 1,5 a 2 vezes maior pode ser observada (Seixas et al., 2011).

\subsubsection{Exposição dos dentes em repouso}

A exposição dos incisivos centrais superiores durante o repouso é, em torno, de 3 a 4 mm nas mulheres jovens e de 2 mm nos homens jovens, tendendo a diminuir com o avançar da idade (Silberberg et al., 2009). Para verificar mais minuciosamente este aspecto, pode-se lançar mão de uma radiografia cefalométrica lateral, medindo a distância entre a borda inferior labial superior em repouso até a borda incisal do incisivo. A grande exposição desses dentes em repouso, pode indicar extrusão dentária, pacientes dolicocéfalos, com crescimento excessivo vertical maxilar ou um lábio superior curto (Seixas et al., 2011).

\subsubsection{Relação harmônica das arcadas dentárias}

A borda incisal dos dentes anterossuperiores e a altura da face oclusal dos dentes posterossuperiores, devem apresentar uma relação harmônica, sem grandes diferenças. A altura da borda incisal maior que a altura oclusal sugere extrusão dos incisivos e/ou sobremordida exagerada (Silberberg et al., 2009).

\subsubsection{Proporção altura/largura dos incisivos}

As proporções altura/largura dos incisivos, poderão ajudar a afirmar se uma coroa clínica curta sofreu desgastes incisais ou sobre a posição inadequada da gengiva marginal (Silberberg et al., 2009). A altura média dos incisivos centrais superiores é, nos homens, de 10,6 mm e, nas mulheres, de 9,8mm; a largura proporcional para esses tamanhos seria cerca de $80 \%$ do comprimento total, com uma margem de $65 \%$ a $85 \%$ dentro do aceitável (Sabri, 2005; Seixas et al., 2011). 


\subsubsection{Tecidos periodontais}

Para examinar o tecido periodontal, é necessário que o clínico verifique se a altura das margens gengivais dos incisivos centrais superiores está igual ou ligeiramente abaixo da margem dos caninos e abaixo da margem dos incisivos laterais. Desgastes incisais, anquiloses por traumas E grandes apinhamentos podem gerar discrepâncias na margem da gengiva (Sabri, 2005). Também é necessário avaliar a largura e a espessura gengival, realizar sondagens para verificar o nível de inserção clínica e o nível da crista óssea alveolar, além de identificar O fenótipo periodontal (Silberberg et al., 2009).

\subsection{Técnicas corretivas do sorriso gengival}

Para que o tratamento do sorriso gengival seja realizado, é indispensável que o clínico tenha entendimento de todas as etiologias inerentes a essa entidade clínica, e compreenda que múltiplos fatores podem estar presentes simultaneamente. Um correto diagnóstico é crucial para selecionar a técnica mais pertinente ao caso. Etiologias multifatoriais podem exigir múltiplas modalidades de tratamentos para que se alcance um resultado com êxito (Gibson \& Tatakis, 2017). Os métodos de correção podem implicar em gengivoplastias, ressecção ósseas, técnicas para reduzir a elevação labial superior, abordagens maxilofaciais e terapias ortodônticas (Mazzuco \& Hexsel, 2010).

\subsubsection{Alongamento coronário}

O alongamento coronário é um procedimento cirúrgico que tem como objetivo aumentar a coroa clínica dos dentes, através da remoção do tecido gengival (Abou-Arraj \& Souccar, 2013). Algumas considerações pré-cirúrgicas devem ser tidas durante o planejamento de um alongamento coronário: a avaliação da largura de tecido gengival queratinizado (deve-se preservar uma quantidade de, aproximadamente, 2 a $3 \mathrm{~mm}$ de gengiva inserida, principalmente em fenótipos gengivais finos); a distância entre a crista óssea alveolar e a JCE (essa distância, medida através da sondagem transgengival, indica se existe violação do espaço biológico); a relação coroa-raiz (a remoção de osso em raízes curtas ou pobres nessa relação, tem consequências negativas, podendo gerar mobilidade dentária); identificar o fenótipo gengival (mensurar a espessura do tecido gengival para prevenir recessões gengivais no pós-operatório); e a espessura da tábua óssea alveolar (uma tábua óssea mais delgada, promove uma maior perda óssea pela reabsorção que ocorre no pós-operatório) (Majzoub et al., 2014).

Três técnicas de alongamento coronário são propostas para o tratamento da exposição excessiva gengival: a gengivectomia, o retalho posicionado apicalmente (RPA) com ou sem ressecção óssea (Abou-Arraj \& Souccar, 2013).

\subsubsection{Gengivectomia}

A gengivectomia é a técnica de escolha quando deseja-se remover tecido gengival, em pacientes com nível ósseo adequado e com a margem gengival localizada a mais de $3 \mathrm{~mm}$ da crista óssea; em que essa distância seja reduzida para $3 \mathrm{~mm}$ após realização da cirurgia (Dolt \& Robbins, 1997). Uma avaliação detalhada e cuidadosa deve ser realizada antes que a gengivectomia seja feita, para que o tecido gengival queratinizado se mantenha após o procedimento (Silberberg et al., 2009).

O procedimento se inicia com aplicação de anestesia local na área cirúrgica, e, com uma sonda milimetrada periodontal, são marcados em diversas regiões no tecido gengival, pontos mais apicais para delimitar o local da incisão (Figura 3) (García et al., 2006). A primeira incisão é feita, seguindo as referências demarcadas no tecido, em bisel interno, contornado cada dente a nível da JCE e seguindo a sua topografia. Para atingir uma estética satisfatória, a altura da incisão, medida a partir da margem gengival, é normalmente diferente para cada dente. Uma segunda incisão é feita no interior do sulco gengival dos dentes, formando um colar gengival ("colarinho") que deve ser retirado com uma cureta periodontal (Abou-Arraj \& Souccar, 2013). Após isso, são feitas sondagens para verificar a localização da crista óssea alveolar em relação a nova margem gengival, que deve medir de 2,5 a $3 \mathrm{~mm}$, para a formação do tecido de inserção supracrestal, antigo espaço biológico (Majzoub et al., 
2014). O valor mínimo de $2 \mathrm{~mm}$ pode ser utilizado, mas pode haver um novo crescimento da margem gengival para comportar o espaço para o sulco gengival (Abou-Arraj \& Souccar, 2013). Geralmente não há necessidade de suturar os tecidos nessa técnica, pois não se rebate retalho (Figura 4) (García et al., 2006).

Figura 3. Demarcação do tecido gengival com a sonda milimetrada, para delimitar o local da incisão.
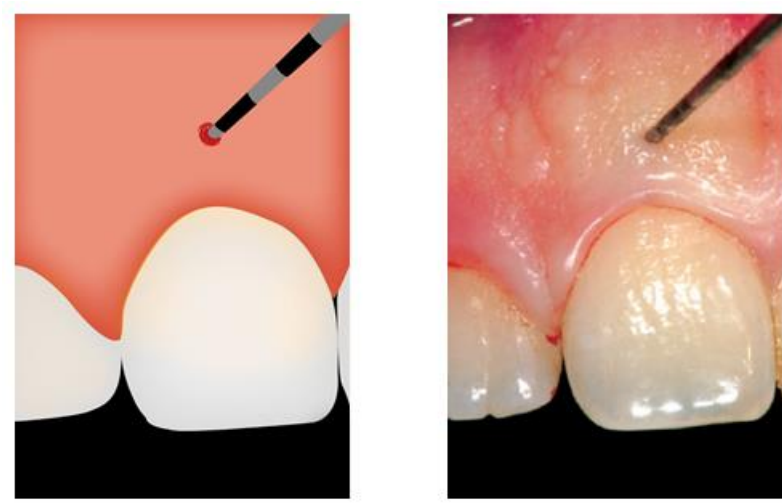

Fonte: Autoria própria. 
Figura 4. Etapas da gengivectomia. Imagem A: esquema inicial do paciente com sorriso gengival; Imagem B: sonda periodontal delimitando a região do zênite gengival; Imagem C: marcações realizadas com a sonda periodontal, delimitando onde ocorrerá a incisão; Imagem D: caminho que a lâmina deverá percorrer; Imagem E: incisão em bisel interno; Imagem F: visão da incisão em bisel interno, a ponta da lâmina deve estar voltada para a cista óssea; Imagem G: aspecto final.
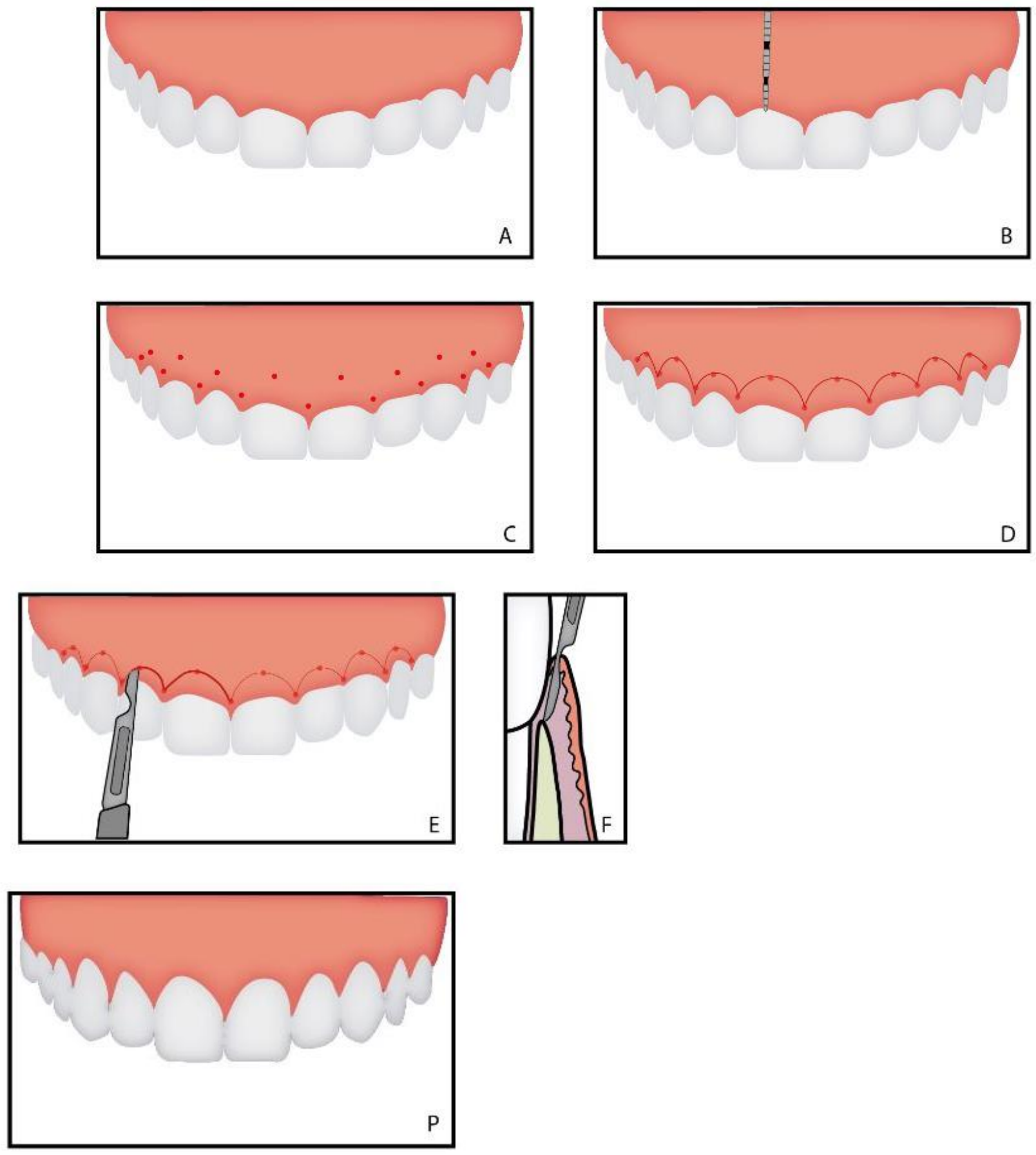

Fonte: Autoria própria. 
O clínico pode optar em realizar a gengivectomia com bisturi ou laser, elegendo o instrumento que tiver mais afinidade. A incisão deve começar nos incisivos centrais superiores; seguindo para incisivos laterais, onde a incisão deve ter cerca de $1 \mathrm{~mm}$ a menos que os centrais; nos caninos, a incisão deve seguir na mesma altura que nos incisivos centrais (AbouArraj \& Souccar, 2013). O tecido gengival é removido primeiramente em um dos lados (direito ou esquerdo), para expor a nova anatomia em contraposto com gengiva em excesso (Rossi et al., 2014).

Uma guia cirúrgica em resina acrílica ou em silicone pode ser confeccionada antes da cirurgia, para estabelecer a extensão de cada dente após a gengivectomia, definindo assim a altura das incisões durante o procedimento (Figura 5). Esta dá ao cirurgião-dentista, a noção do aspecto final de cada caso antes que a cirurgia seja realizada e facilita a execução do desenho da nova margem gengival (Oliveira et al., 2015; Majzoub et al., 2014).

Figura 5. Guia cirúrgica em resina acrílica.

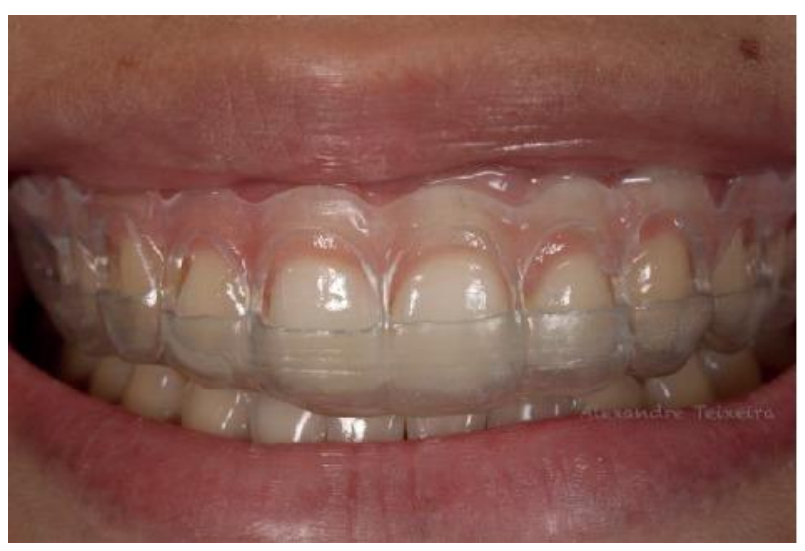

Fonte: Autoria própria.

A gengivectomia está indicada quando há tecido gengival em excesso e o nível ósseo alveolar está normal e, por isso, se aplica nos casos de EPA do tipo 1A (Silberberg et al., 2009). Em tecidos gengivais mais espessos, deve-se ter cautela, pois eles tendem a regredir com mais frequência que os tecidos gengivais mais delgados (Abou-Arraj \& Souccar, 2013).

\subsubsection{Retalho posicionado apicalmente sem ressecção óssea}

O retalho posicionado apicalmente (RPA) sem ressecção óssea é a técnica de eleição quando o indivíduo apresenta um nível ósseo adequado, porém uma cirurgia de gengivectomia deixaria menos de $3 \mathrm{~mm}$ de distância entre a margem da gengiva e a crista óssea. Então, ao contrário do que acontece na gengivectomia, o RPA visa preservar a maior quantidade de tecido gengival queratinizado possível (Silberberg et al., 2009; Abou-Arraj \& Souccar, 2013).

Antes da cirurgia, é feita a anestesia local na região cirúrgica. A incisão inicial poderá acontecer de duas formas, dependendo da simetria do contorno gengival: se o contorno gengival for assimétrico, a primeira incisão é feita como na gengivectomia (contornando os dentes no nível da JCE), para criar essa simetria no tecido gengival após procedimento, caso o indivíduo apresente um contorno simétrico antes da cirurgia, a primeira incisão feita deve ser no interior do sulco gengival. Feita a incisão intra sulcular, o tecido gengival deve ser descolado, formando uma incisão em envelope, que se estenderá apicalmente até a junção mucogengival para dar mobilidade ao retalho. O clínico pode ainda realizar incisões relaxantes nas regiões distais da área para auxiliar no posicionamento apical. O retalho é, por fim, posicionado apical a JCE e suturado (Figura 6) (Dolt \& Robbins, 1997; Abou-Arraj \& Souccar, 2013). 
Figura 6. Etapas do RPA sem ressecção óssea. Imagem A: fotografia inicial do paciente com sorriso gengival sorrindo; Imagem B: fotografia intraoral; Imagem C: tecido incisado na região dos dentes 11, 12 e 13, e colar gengival eliminado na região dos dentes 21, 22 e 23; Imagem D: tecido descolado, formando uma incisão em envelope; Imagem E: tecido reposicionado e suturado; Imagem F: fotografia final da paciente com sorriso gengival sorrindo, 7 dias após a realização da cirurgia.
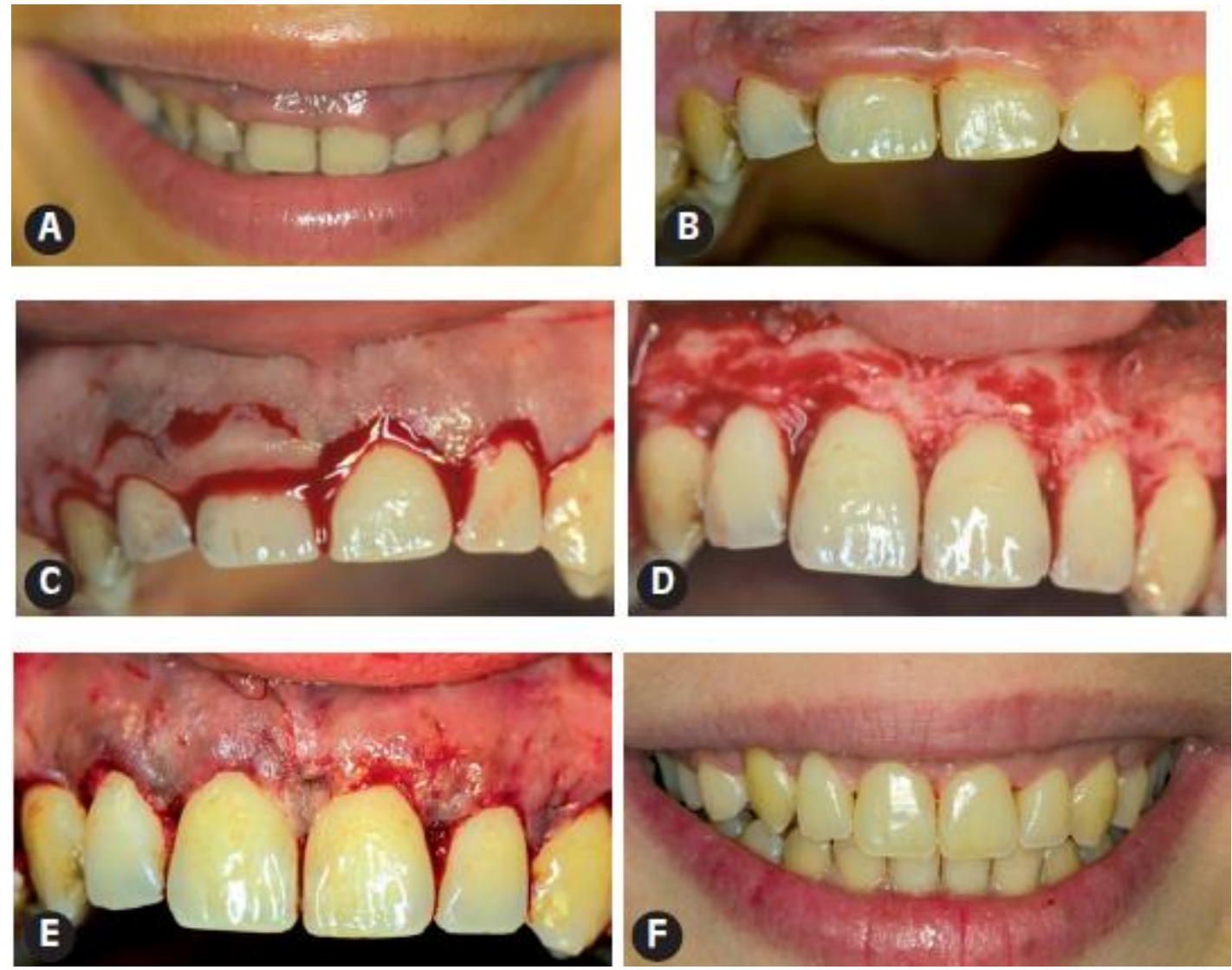

Fonte: García et al. (2006).

Essa técnica está indicada para casos em um volume gengival e nível ósseo alveolar normal, ou seja, em Erupção passiva alterada (EPA) do tipo 2A (Silberberg et al., 2009).

\subsubsection{Retalho posicionado apicalmente com ressecção óssea}

O retalho posicionado apicalmente com ressecção óssea é a técnica recomendada para os casos em que a crista óssea alveolar está próxima da JCE, e, por isso, a ressecção óssea se faz necessária para formação do tecido de inserção supracrestal (Silberberg et al., 2009). Para os periodontistas, essa técnica de alongamento é a mais utilizado para o tratamento da exposição excessiva da gengiva. Ele une os benefícios e etapas das duas técnicas anteriores, e é finalizado com recontorno ósseo para atingir a estética periodontal ideal (Abou-Arraj \& Souccar, 2013).

O procedimento começa com aplicação de anestesia local na área cirúrgica. Como na técnica do RPA, a primeira incisão dependerá da simetria da margem da gengiva que o paciente apresenta no pré-operatório, podendo então: contornar os dentes para corrigir a assimetria, como é feito na gengivectomia; ou iniciar com uma incisão intra sulcular, quando já existe simetria. O tecido gengival é descolado até a linha mucogengival, formando uma incisão em envelope. A posição do osso alveolar em relação a nova margem gengival é novamente sondada antes da ressecção, e, usando brocas e cinzéis, o contorno ósseo é refeito (seguindo a JCE): primeiro nos incisivos centrais, seguido pelos caninos e terminando nos incisivos laterais; 
sempre que os pré-molares estiverem incluídos na cirurgia, devem ser os últimos a sofrerem ressecção óssea. A remoção de osso é feita até que a crista óssea fique de 2 a 2,5 mm apical da JCE, espaço suficiente para criar o espaço biológico (AbouArraj \& Souccar, 2013). O tecido gengival então é reposicionado apicalmente a JCE, uma nova sondagem é feita para confirmar se a distância entre a margem gengival e a crista óssea está correta, e, por fim, é suturado (Figura 6) (Dolt \& Robbins, 1997).

Dois termos podem ser utilizados para descrever a ressecção óssea: osteoplastia e ostectomia. A osteoplastia consiste na remoção de osso para criar uma forma fisiológica, sem remover osso de suporte, ou seja, a espessura do osso alveolar é retirada, mas não há remoção de osso diretamente ligado a raiz dentária pelo ligamento periodontal. A ostectomia é a remoção do osso de suporte para reparar deformidades; e pode ser feita com diversos instrumentais, como brocas, cinzéis e motores piezoelétricos, por exemplo (Majzoub et al., 2014).

Essa técnica está indicada sempre que a distância entre a crista óssea e a JCE for menor que $1 \mathrm{~mm}$ (se a crista óssea não estiver apical a JCE, esse valor será negativo e, portanto, <1 mm); então, será indicado para EPA do tipo 1B e 2B (Cairo et al., 2012; Garber \& Salama, 2000; Darakh et al., 2017).

Figura 7 - Indica a sequência de procedimentos para realização de gengivoplastia seguida por retalho mucoperiosteal e osteotomia.
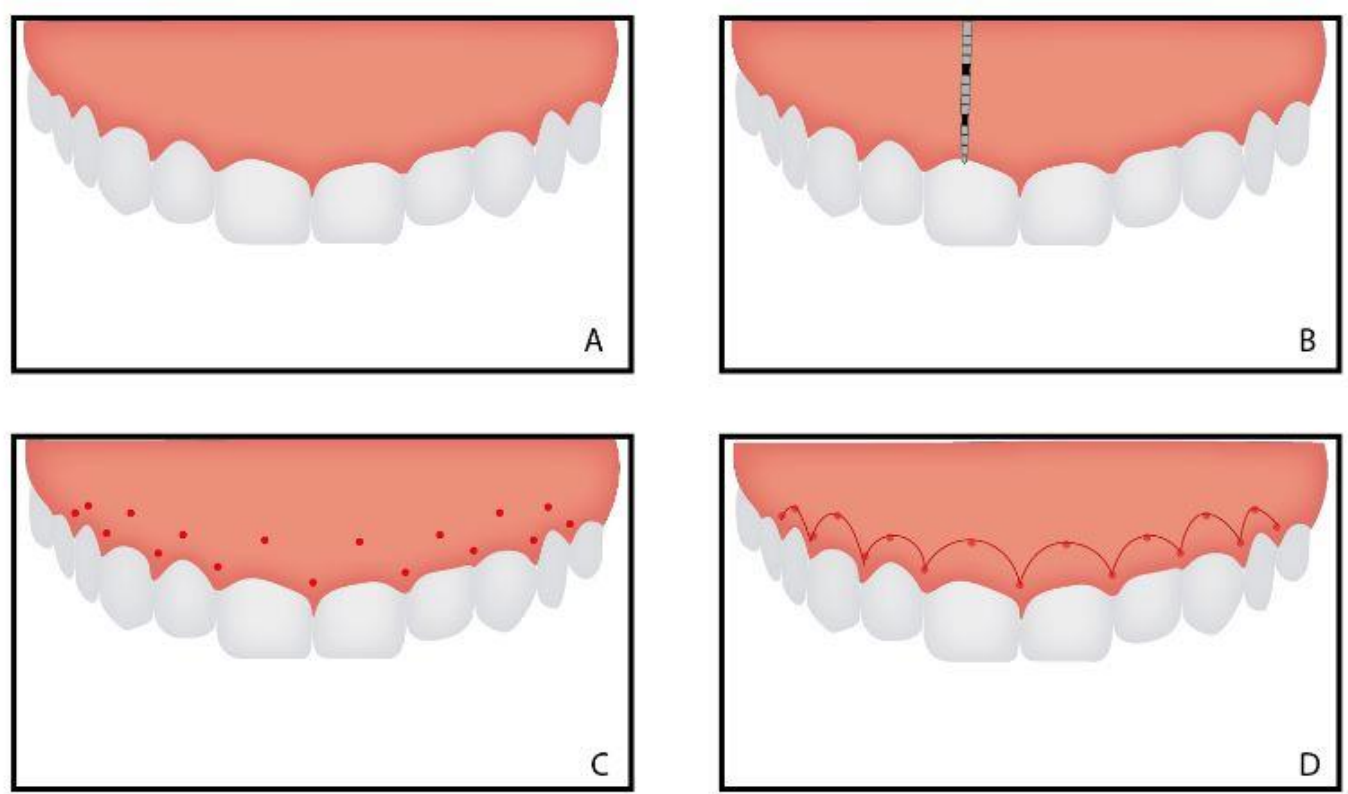

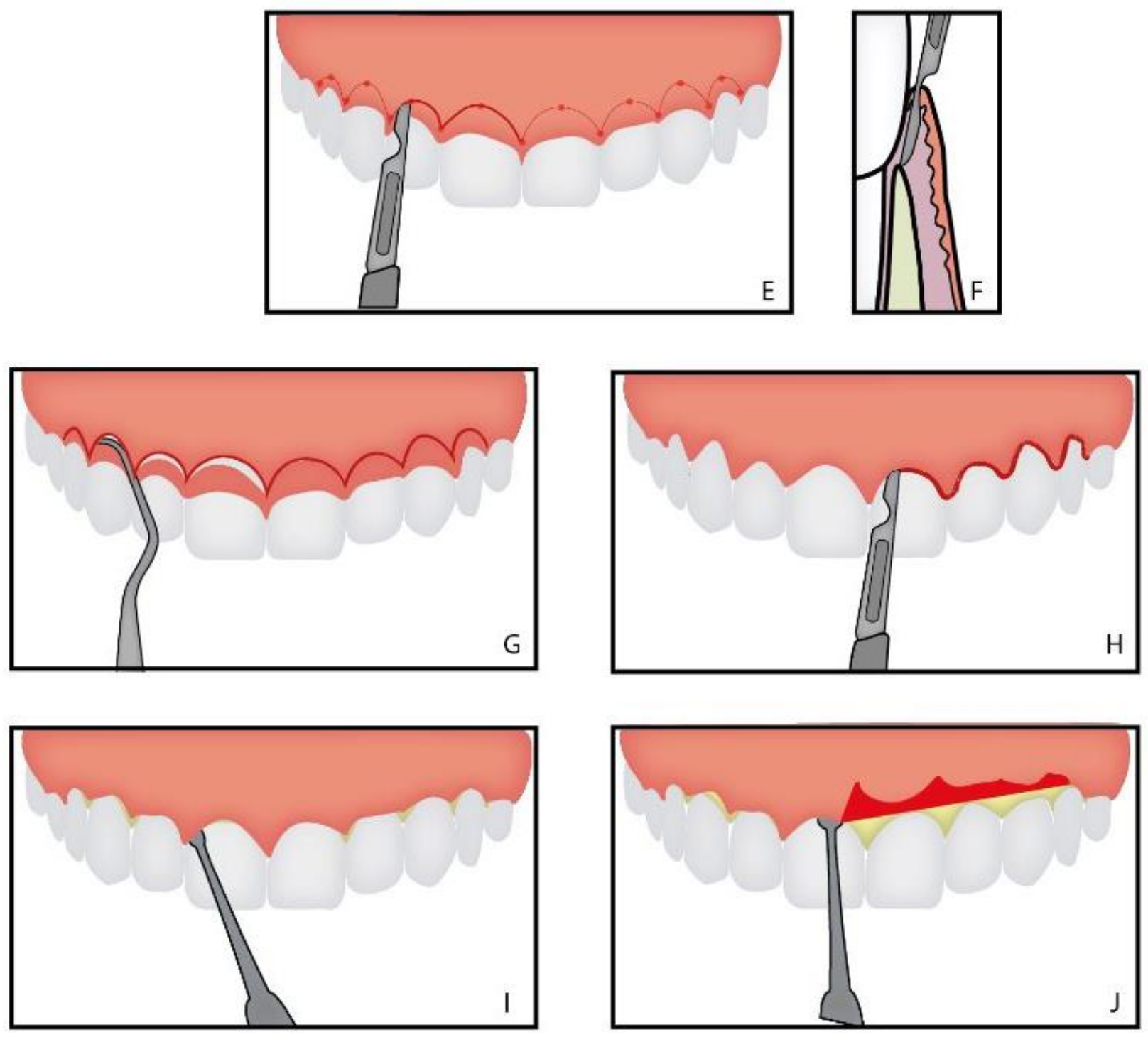

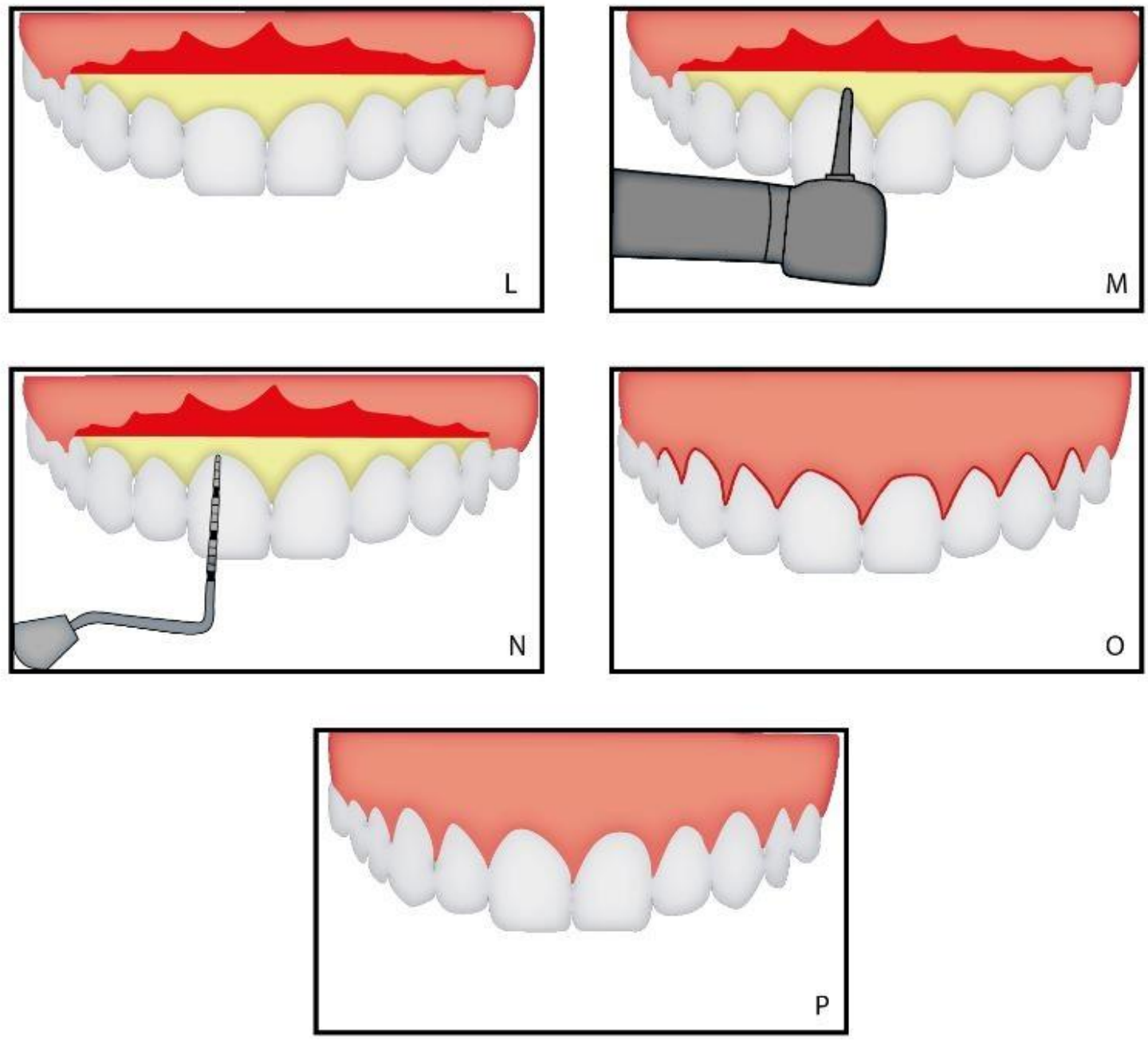

Fonte: Autoria própria.

\subsubsection{Técnica de Flapless}

O tratamento mais indicado para os indivíduos que possuem sorriso gengival causado por erupção passiva alterada é a cirurgia de aumento de coroa clínica, com o propósito de aumentar a coroa dentária através da remoção de tecido gengival e tecido ósseo quando houver alteração na topografia óssea (Galdino et al., 2021; Lemes et al., 2018). Dentre as técnicas cirúrgicas disponíveis a técnica convencional de aumento de coroa clínica com elevação de retalho mucoperiosteal é a mais utilizada. Esta técnica expõe o osso alveolar para realizar a osteotomia e osteoplastia, sendo necessário à realização de suturas posteriormente (Galdino et al., 2021).

Além da técnica convencional existe uma nova técnica, a técnica de cirurgia periodontal sem retalho, mais conhecida por sua descrição internacional "Flapless". A técnica de "Flapless" é um procedimento minimamente invasivo, que consiste no 
estudo e planejamento do caso, com o auxílio de tomografia cone beam, para visualização da crista óssea e realização da osteotomia. Esta técnica dispensa a necessidade de elevação do retalho mucoperiosteal. A osteotomia é realizada via sulco gengival com a utilização de microcinzéis, após a osteotomia é realizada uma nova sondagem até a crista óssea confirmando o reestabelecimento da distância biológica. A finalização do procedimento não requer a necessidade de suturas pois não há rompimento dos tecidos que unem as papilas interdentais (Galdino et al., 2021; Lemes, et al., 2018).

Essa técnica é indicada para casos de pacientes com fenótipo periodontal fino ou intermediário e traz como vantagens a não necessidade da sutura final e redução da morbidade cirúrgica, proporcionando assim, um pós-operatório mais confortável (Galdino et al., 2021). Nos indivíduos com fenótipo periodontal espesso, é contraindicada essa técnica devido à realização da osteoplastia e a necessidade de grande remoção óssea, muitas vezes sendo necessário a utilização de brocas para realizar a osteotomia/osteoplastia. Uma desvantagem da técnica "Flapless" é a complexidade do procedimento e a delicadeza da técnica, devendo ser criteriosa e não podendo haver erros na incisão, para possibilitar uma perfeita delimitação da futura margem gengival. Outra dificuldade é a não visualização da crista óssea, exigindo grande habilidade e destreza do cirurgião e uma exatidão no momento da osteotomia (Lemes et al., 2018).

Durante a técnica de "Flapless" os cinzéis podem ser substituídos por um dispositivo piezoelétrico com configuração específica. A técnica de osteotomia através de piezocirurgia torna-se mais previsível, pois as micro vibrações permitem um corte preciso apenas de estruturas mineralizadas, sem danificar os tecidos moles, mesmo em caso de contato acidental, além de diminuir o sangramento local e as respostas inflamatórias, como edema e dor. Na piezocirurgia também é possível contar com uma ponta periodontal específica com marcação de $3 \mathrm{~mm}$ que pode orientar o clínico para uma osteotomia mais precisa e segura (Deliberador et al., 2020).

\subsection{Técnicas que limitam a função muscular labial superior}

\subsubsection{Toxina botulínica}

A toxina botulínica é uma neurotoxina sintetizada pela bactéria Clostridium botulinum, uma bactéria anaeróbica grampositiva. Essa substância atua bloqueando a liberação de acetilcolina, o principal neurotransmissor da junção neuromuscular, impedindo a contração muscular. A fraqueza muscular causada pelo uso da toxina botulínica estimulou seu uso em casos em que existe hiperatividade muscular. Existem oito diferentes de exotoxinas (A, B, C1, C2, D, E, F e G), porém, o sorotipo A é o mais potente e o mais utilizado na clínica (Nigam \& Nigam, 2010).

Na odontologia, a toxina começou a ser utilizada com fins terapêuticos, pois é uma eficiente terapêutica para diversas condições, como hipertrofia do masseter, bruxismo, dor miofacial e disfunção temporomandibular (Pedron, 2016). Também é aplicada para os casos de sorriso gengival, representando uma forma de correção simples, rápida e eficiente (Mazzuco \& Hexsel, 2010).

Consiste em uma técnica simples de ser aplicada, que consiste em uma injeção no músculo (geralmente no músculo elevador do lábio superior e da asa do nariz, o zigomático maior e o zigomático). Os locais da injeção são determinados enquanto o paciente mantém o lábio superior em função, ou seja, sorrindo, e palpando os músculos contraídos para garantir uma localização precisa (Figura 8). A toxina botulínica-A é um pó hidrofílico, que é diluído, conforme as recomendações do fabricante, em solução salina (cloreto de sódio a $0,9 \%$ ), e injetado nos sítios escolhidos. O procedimento pode ser feito com anestesia tópica (lidocaína ou prilocaína). Os efeitos clínicos surgem cerca de 2 a 10 dias após a aplicação das injeções (Figura 9) (Polo, 2008; Pedron, 2016). 
Figura 8. Definindo os locais da injeção com o lábio superior em função.

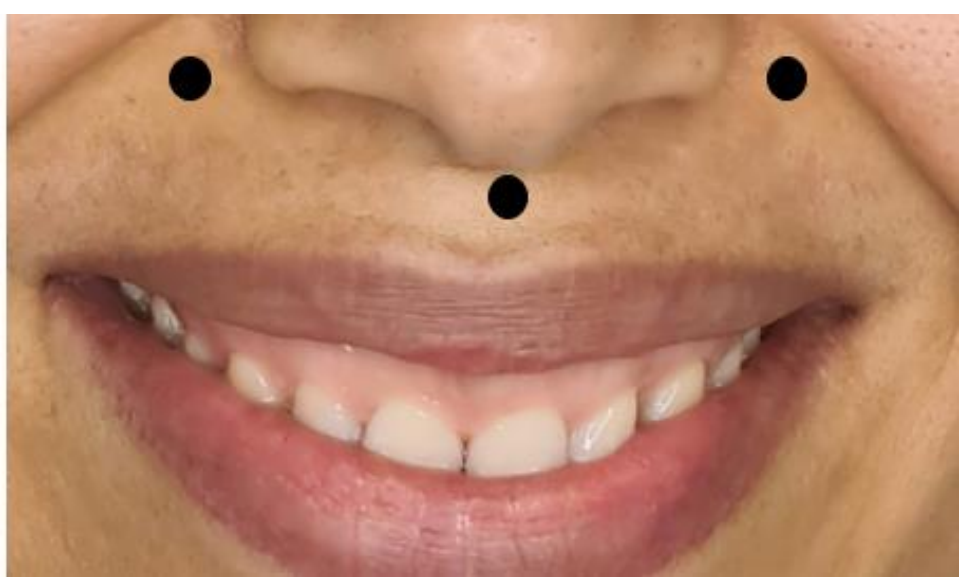

Fonte: Autoria própria.

Figura 9. Fotografias realizadas antes da aplicação (superior) e 14 dias após a aplicação da toxina botulínica (inferior).
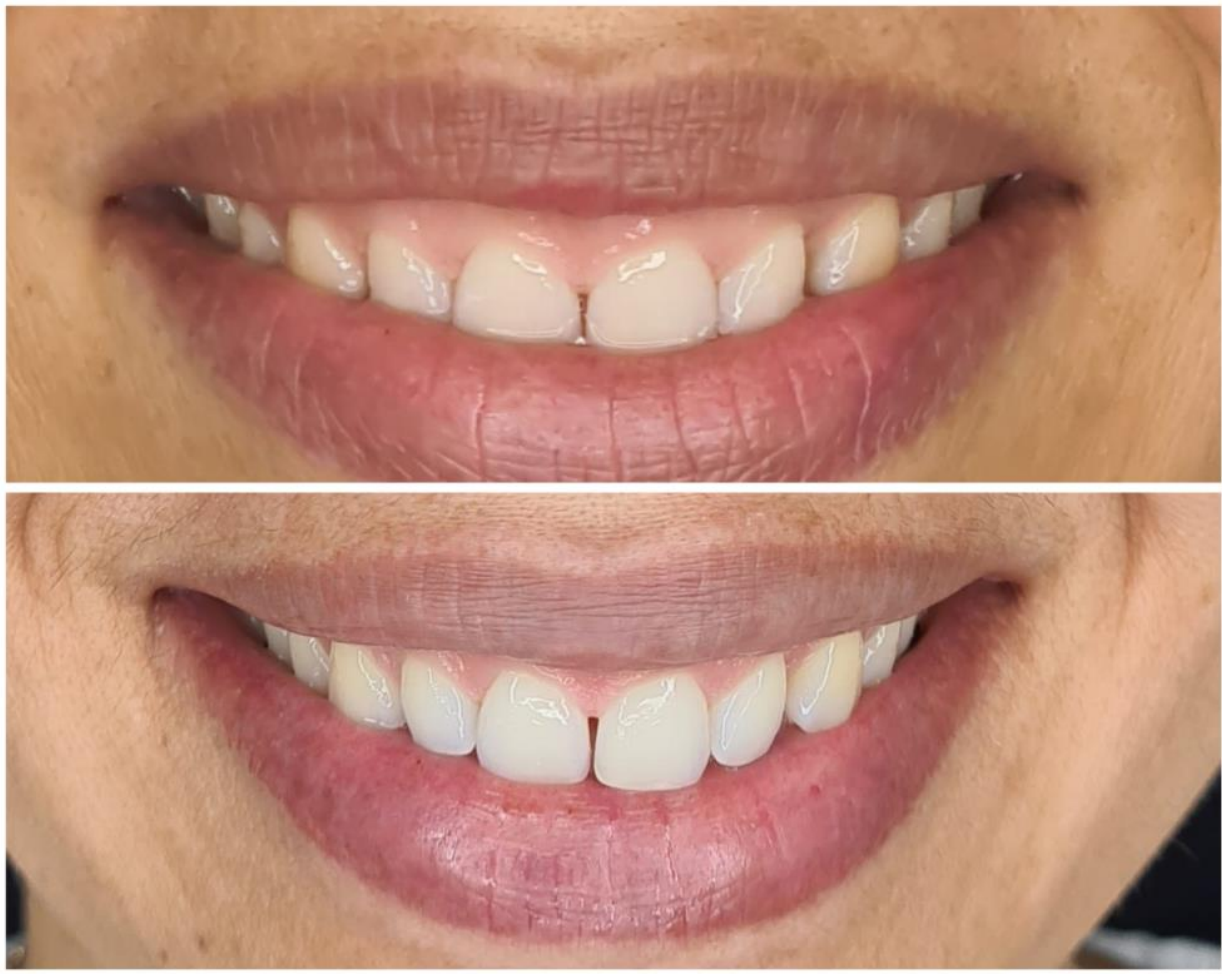

Fonte: Autoria própria.

Segundo Pedron (2016), a ato de sorrir é fruto da ação de diferentes músculos faciais, como o elevador do lábio superior e da asa do nariz, o zigomático maior, o zigomático menor, o elevador do ângulo da boca, o risório e o orbicular da boca; mas os três primeiros são os de maior função e vão determinar quanto de elevação do lábio o paciente vai ter. Portando, o elevador do lábio superior e da asa do nariz, o zigomático maior e o zigomático menor são frequentemente os músculos-alvo da toxina.

As vantagens desse método de correção é a facilidade e segurança das aplicações, ser pouco invasivo e mais conservador; ser um procedimento rápido e possuir um preço razoável. Em contrapartida, seu efeito é temporário (com duração de até 6 meses), representando uma terapêutica não-definitiva, e que deve ser repetida para que os resultados sejam mantidos (Almasri, 2015). 
O uso da toxina botulínica para tratar a exposição excessiva gengival pode ser classificado de três formas: corretivo, quando a causa é unicamente muscular; adjuvante, quando mais de uma causa está presente; ou paliativo, quando o tratamento recomendado é a cirurgia (Mazzuco \& Hexsel, 2010).

A técnica está indicada como tratamento de primeira escolha para sorrisos gengivais provocados pela hiperfunção muscular e está contraindicada em mulheres grávidas ou que estão no período de amamentação; pacientes que possuem miastenia gravis e a síndrome de Lambert Eaton; bem como pacientes que possuem hipersensibilidade a algum componente da fórmula; e que fazem uso de antibióticos da classe dos aminoglicosídeos, a técnica também é contraindicada (Pedron, 2016; Sevilha et al., 2011).

\subsubsection{Técnica do reposicionamento labial}

A técnica de reposicionamento labial constitui uma forma de tratamento do sorriso gengival originado pelo lábio superior hiperativo. Este procedimento foi descrito pela primeira vez em 1973, por Rubinstein e Kostianovsky, na literatura da cirurgia plástica; e, recentemente, foi publicado na literatura odontológica (Gaddale et al., 2014).

A finalidade dessa cirurgia é limitar a ação dos músculos. Isso é feito retirando uma tira de mucosa do vestíbulo e tornando-o mais superficial, consequentemente, a tração de músculos, como zigomático menor, elevador do ângulo da boca, orbicular da boca e elevador do lábio superior, fica restringida; limitando assim a exposição da gengiva ao sorrir (Dayakar $e t$ al., 2014; Gaddale et al., 2014).

O procedimento começa com aplicação de anestesia por infiltração local na mucosa vestibular e no lábio, do primeiro molar superior esquerdo ao primeiro molar superior direito. O sítio cirúrgico é definido, utilizando um lápis estéril no tecido seco. A primeira incisão é feita na junção mucogengival, na horizontal, entre os primeiros molares superiores. A segunda incisão é feita paralela a primeira, na mucosa labial, a, aproximadamente, 10-12 mm de distância da primeira incisão. As duas incisões horizontais são conectadas nas extremidades através de duas incisões verticais, criando um contorno elíptico. A tira de mucosa é então removida por meio de uma dissecção superficial, deixando o tecido conjuntivo exposto. Quando necessário, as glândulas salivares menores devem ser removidas, pois seu rompimento pode ocasionar posteriormente uma mucocele. O tecido é suturado com suturas interrompidas na linha média, alinhando a linha média labial e dentária, e em outros pontos de estabilização; e também com sutura contínua para aproximar toda área incisada (Simon et al., 2007; Gaddale et al., 2014).

Devido à alta morbidade causada por essa cirurgia e pela dificuldade de estabilização da linha média labial, foi introduzida uma modificação da técnica original de Rubinstein e Kostianovsky. A técnica do reposicionamento labial modificada consiste na remoção de duas tiras mucosas, bilateralmente ao freio labial superior até a região do primeiro molar superior e reposicionamento das novas margens de mucosa (Silva et al., 2013).

\subsubsection{Reposicionamento labial com cimento ósseo à base de polimetilmetacrilato (PMMA)}

Recentemente, uma nova técnica cirúrgica para o manejo do sorriso gengival foi proposta por Naldi et al. (2010), essa técnica consiste na implantação de enxerto de cimento ósseo com base em polimetilmetacrilato (PMMA) na maxila anterior abaixo da abertura piriforme (Torres et al., 2020).

O supercrescimento maxilar pode causar uma depressão esquelética subnasal, que permite o lábio superior se alojar no ato de sorrir espontaneamente, dessa forma o lábio superior é retraído ao sorrir, causando uma exposição de gengiva excessivamente. $\mathrm{O}$ enxerto de cimento ósseo à base de PMMA preenche essa depressão, atuando como material obturador da depressão subnasal, proporcionando novo suporte labial e evitando o deslocamento excessivo do lábio superior durante a contração, o que torna a técnica eficaz para a reabilitação com fins estéticos (Torres et al., 2020; Arcuri, Costa, Ribeiro, Barreto, \& Lyra e Silva, 2018). 
O cimento ósseo à base de PMMA tem sido utilizado desde a Segunda Guerra Mundial em diversas especialidades da saúde, como na neurocirurgia e ortopedia. Atualmente o cimento ósseo a base de PMMA ainda é o material reconstrutivo mais utilizado por profissionais por ser um dos produtos aloplásticos mais biocompatíveis disponíveis, induzindo baixa reação de corpo estranho e fornecendo proteção adequada aos tecidos neurais adjacentes. A primeira indicação para seu uso em odontologia foi para próteses totais e desde então tem demonstrado resultados positivos, incluindo alta biocompatibilidade com os tecidos bucais. Atualmente na odontologia, o PMMA tem sido usado para aparelhos ortodônticos, próteses, próteses definitivas e provisórias parciais e totais, bem como para próteses maxilofaciais e fixação de fraturas mandibulares (Arcuri et al., 2018).

Após o aumento de coroa clínica, o cimento ósseo à base de PMMA é preparado com gentamicina em uma cubeta cirúrgica estéril, quando a mistura para de grudar nas luvas cirúrgicas, ela é posicionada na fosseta subnasal, sob abundante irrigação com solução salina resfriada para garantir a presença de uma interface úmida entre o PMMA e os tecidos. Com o cimento posicionado é aguardada a polimerização completa sob abundante resfriamento e logo após é realizado o refinamento e acabamento da prótese de PMMA com brocas Maxicut e Minicut. A prótese deve atingir o volume máximo de 7mm. Após atingir o tamanho e formato ideal, a prótese é fixada no osso com parafusos de fixação à base de titânio, idênticos aos utilizados em procedimentos de enxerto ósseo (Figura 10) (Arcuri et al., 2018).

Figura 10 - Cimento ósseo à base de PMMA fixado na fosseta subnasal.

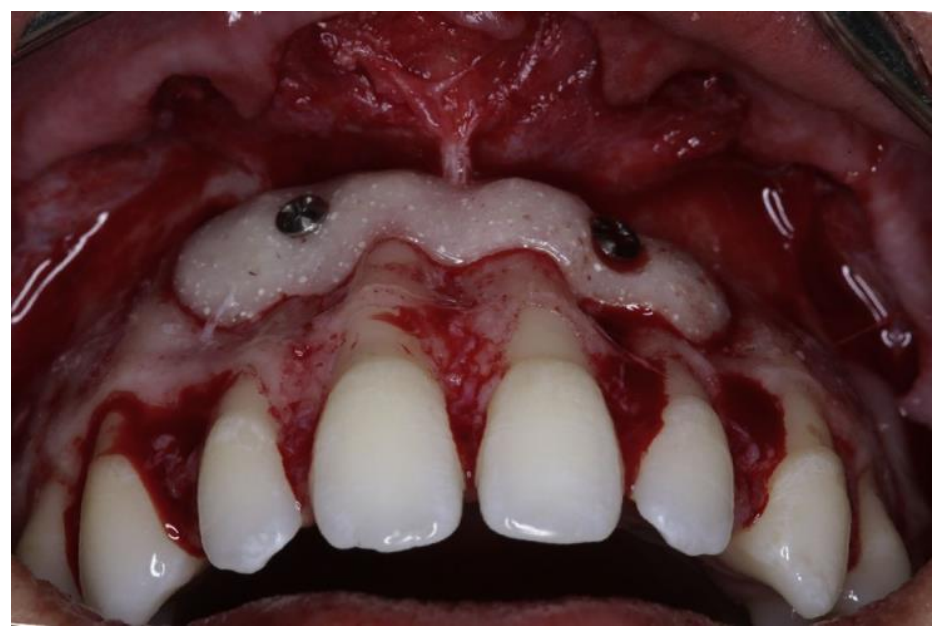

Fonte: Adaptada de Arcuri, et al. (2018).

Durante a manipulação intraoperatória do cimento de PMMA, os tecidos podem ser danificados quando expostos a essas altas temperaturas, nas quais o tempo de exposição é determinante. A mistura de n-dimetil-p-toluidina e peróxido de benzó́la resulta na formação do PMMA e durante este processo é liberado calor. As temperaturas liberadas durante o processo podem variar e as reações exotérmicas podem chegar a $100^{\circ} \mathrm{C}$. Desta forma a reação exotérmica pode desencadear eventos inflamatórios e necrose dos tecidos adjacentes ao PMMA. Para evitar complicações decorrentes de reações exotérmicas, também podem ser utilizadas placas pré-fabricadas, baseadas em dados tomográficos do defeito ósseo ou em modelos obtidos previamente, a fim de minimizar o risco de necrose do tecido (Arcuri et al., 2018).

\section{Discussão}

O estudo tem como finalidade abordar o diagnóstico, bem como as técnicas de correção da exposição excessiva gengival, já que é uma temática cada vez mais abordada e de uma alta demanda nos consultórios odontológicos já que a busca 
por um sorriso mais estético e agradável se encontra cada vez maior, fazendo-se fundamental que o dentista detenha de conhecimento para sucesso na terapêutica.

Em relação aos parâmetros clínicos classificatórios da exposição gengival excessiva há divergências na literatura. Segundo alguns autores, quando se apresenta uma exposição de gengiva superior a $2 \mathrm{~mm}$, a condição de sorriso gengival já é detectada (Liébart et al., 2004). Outros autores como Pedron (2016) afirma que essa exposição deve ser maior que 3 mm e Van der Geld et al. (2011) maior que 4 mm, então dessa forma não existe uma unanimidade ideal de escolha ideal para classificar o sorriso gengival. Avaliação dos tecidos moles e ósseos facial, também são necessárias, assim como uma avaliação da cavidade oral: dentição/ tecidos gengivais, e relação labial com essas estruturas (Panossian \& Block, 2010).

Os termos sorriso alto e sorriso gengival podem ser confundidos e utilizados erroneamente. Os indivíduos que possuem um sorriso gengival possuem a linha do sorriso alta, porém o inverso não é aplicado, já que o sorriso gengival traduz uma exposição da gengiva superior a $3 \mathrm{~mm}$ (Braga et al., 2015).

As terapêuticas do caso clínico em questão variam de acordo com as etiologias da exposição excessiva gengival. Em algumas situações, uma abordagem com multidisciplinaridade pode ser mais indicada em casos de múltiplas etiologias (Oliveira et al., 2013).

Em relação as técnicas de correção do sorriso gengival, a extrusão dentoalveolar é tratada com reposionamento ortodôntico, que consiste na intrusão dos dentes que sobre erupcionaram. Na medida que os dentes vão intruindo, a margem gengival se move apicalmente. O tratamento também pode incluir uma correção periodontal cirúrgica (Silberberg et al., 2009).

A erupção passiva alterada é normalmente tratada através de uma cirurgia periodontal: o alongamento coronário. A modalidade de alongamento coronário selecionada diverge conforme o tipo de EPA. Para EPA do tipo 1A, é indicado a gengivectomia; para EPA do tipo 2A, é recomendado a cirurgia de retalho posicionado apicalmente sem ressecção óssea; e para os tipos 1B e 2B, são indicados a cirurgia de retalho posicionado apicalmente com ressecção óssea (Silberberg et al., 2009). A extrusão ortodôntica também pode fazer parte do tratamento, quando, durante o planejamento, o cirurgião-dentista verificar que no pós-operatório, a ressecção óssea irá provocar um desnivelamento da margem gengival, gerando assimetrias que comprometem a estética (Dolt \& Robbins, 1997).

Quando o sorriso gengival se origina através da hiperplasia gengival induzido por biofilme dentário, o controle de placa dentária e inflamação é a primeira etapa do tratamento. A escovação dentária e o uso do fio dental reduzem significativamente a placa bacteriana e a inflamação gengival; após isso é possível quantificar melhor o aumento da gengiva em decorrência da presença do processo inflamatório. Em seguida, é realizado uma gengivectomia (Mishra et al., 2011).

O excesso vertical maxilar é tratado através da cirurgia ortognática em conjunto com o tratamento ortodôntico. Este tratamento oferece uma grande morbidade durante o pós-operatório, por ser uma cirurgia bastante invasiva, e os resultados em geral não são satisfatórios (Suma et al., 2014). Em razão disso, a toxina botulínica tem sido empregada de forma complementar a cirurgia ortognática, melhorando a estética e dando um maior bem-estar (Indra et al., 2011).

Hiperatividade labial e o lábio superior curto podem ser tratados com o uso da toxina botulínica ou através da cirurgia de reposicionamento labial. A toxina botulínica se revelou como uma eficiente forma de combater o sorriso gengival e é o tratamento de primeira escolha para o lábio superior hipertônico, devido a segurança e simplicidade do procedimento, no entanto tem uma curta duração do efeito (3 a 6 meses), exigindo novas aplicações (Pedron, 2016).

A cirurgia de reposicionamento labial limita a elevação do lábio superior, diminuindo a exposição gengival (Silberberg et al., 2009). Dayakar e colaboradores (2014) relataram, através de um caso clínico, que 12 meses após realizar a cirurgia de reposicionamento labial, o lábio superior retorna para a sua posição original. Por esse motivo, mesmo que a exposição gengival seja reduzida nos primeiros meses, essa técnica não possui estabilidade. Modificações da técnica original surgiram para solucionar esse revés, buscando uma maior estabilidade. 


\section{Considerações Finais}

Um sorriso harmônico, relação entre os elementos dentários, gengivais e labial é essencial, portanto, uma exposição maior de gengiva é considerada um desequilíbrio estético e funcional, que pode influenciar também o bem-estar e as relações interpessoais (Espíndola et al., 2021). Portanto, o clínico deve estar habilitado para exercer um correto diagnóstico, com uma etiologia precisa e assim elaborar um planejamento terapêutico para o seu paciente, atendendo as necessidades do ponto de vista estético e funcional, e que esses resultados sejam duradouros.

Atualmente, existem diversas formas de tratamento para a exposição excessiva gengival, que variam desde técnicas menos invasivas, como a utilização da toxina botulínica, a técnicas cirúrgicas mais complexas como gengivoplastias, ressecção óssea, técnicas para reduzir a elevação labial superior, e até abordagens mais invasivas como as cirurgias ortognáticas.

Sendo assim, apesar da diversidade de formas de tratamento o êxito de cada caso se faz por meio de um diagnóstico correto para que seja realizada a indicação correto do tratamento correta para cada paciente. Muitos estudos sobre o diagnóstico e maneiras de corrigir esta problemática ainda se faz necessário, algumas técnicas ainda pouco utilizadas, como o reposicionamento labial, necessitam de estudos clínicos randomizados para buscar um melhor entendimento e, assim, garantir uma Odontologia baseada em evidências, gerando uma autoestima elevada e com qualidade de vida aos pacientes.

\section{Referências}

Abou-Arraj, R. V., \& Souccar, N. M. (2013). Periodontal treatment of excessive gingival display. In Seminars in Orthodontics, 19(4), $267-278$.

Almasri, M. (2015). Surgical techniques to improve the smile. A Textbook of Advanced Oral and Maxillofacial Surgery, $2,2191$.

Arcuri, T., Costa, M. F. P. da, Ribeiro, I. M., Barreto, B. D., Jr, \& Lyra e Silva, J. P. (2018). Labial repositioning using polymethylmethracylate (PMMA)based cement for esthetic smile rehabilitation-A case report. International journal of surgery case reports, 49, $194-204$.

Bidra, A. S., Agar, J. R., \& Parel, S. M. (2012). Management of patients with excessive gingival display for maxillary complete arch fixed implant-supported prostheses. The Journal of prosthetic dentistry, 108(5), 324-331.

Braga, M. S., Nascimento, J. M. Q., Camargo, E. B., Filho, J. M. D. C. V., Falcão, E. P., Zuza, E. P., \& Pires, J. R. (2015). Cirurgia plástica periodontal para correção de erupção passiva alterada. Braz. J Periodontol, 24(4), 64-68.

Cairo, F., Graziani, F., Franchi, L., Defraia, E., \& Pini Prato, G. P. (2012). Periodontal plastic surgery to improve aesthetics in patients with altered passive eruption/gummy smile: a case series study. International journal of dentistry, 2012,837658.

Costa, L. A., Fernandes, G. O., Kanazawa, L. S., Miranda, J. G., \& Pretti, H. (2004). Análise facial-Uma revisão de literatura. J Bras Ortodon Ortop Facial, 9(50), 171-176.

Darakh, P., Khadtare, Y., Waghmare, P., \& Mali, A. (2017). Treatment of altered passive eruption by surgical gingivectomy: A case report. IP Int $J$ Periodontol Implantol, 2(2), 64-68.

Dayakar, M. M., Gupta, S., \& Shivananda, H. (2014). Lip repositioning: An alternative cosmetic treatment for gummy smile. Journal of Indian Society of Periodontology, 18(4), 520.

Deliberador, TM, Weiss, SG, Neto, A., Zetola, IZ, Prix, M., Júnior, DR, Martins, HH, \& Storrer, C. (2020). Cirurgia Periodontal Guiada: Associação de Fluxo de Trabalho Digital e Piezocirurgia para a Correção de um Sorriso Gomoso. Relatos de casos em odontologia, $2020,7923842$.

Dolt, A. H., \& Robbins, J. W. (1997). Altered passive eruption: an etiology of short clinical crowns. Quintessence International, 28(6),363-372.

Espíndola, L. C. P., Fagundes, D. dos S., Lima, V. H. S. de, \& Moreira, T. R. M. dos R. (2021). Etiology and diagnosis of gummy smile - Literature review. Research, Society and Development, 10,17, e223101724798.

Gaddale, R., Desai, S. R., Mudda, J. A., \& Karthikeyan, I. (2014). Lip repositioning. Journal of Indian Society of Periodontology, $18(2), 254$.

Galdino, D. A., de Macedo Bernardino, Í., do Nascimento Barbosa, D., Ferreira, I. J., da Silva, F. A., da Silva, B. D., \& Costa, L. G. C. (2021). Correção do sorriso gengival através do aumento de coroa clínica usando a técnica flapless: Uma revisão integrativa. Research, Society and Development, 10(5), e10210512753-e10210512753.

Garber, D. A., \& Salama, M. A. (1996). The aesthetic smile: diagnosis and treatment. Periodontology 2000, 11, 18-28.

García, I. B., López, M. C. F., Campillo, M. C., \& Ureña, J. I. H. (2006). Erupción pasiva alterada. Implicaciones estéticas y alternativas terapéuticas. RCOE: Revista del Ilustre Consejo General de Colegios de Odontólogos y Estomatólogos de España, 11(5), 563-571. 
Gibson, M. P., \& Tatakis, D. N. (2017). Treatment of gummy smile of multifactorial etiology: A case report. Clinical advances in periodontics, 7(4), 167-173.

Indra, A. S., Biswas, P. P., Vineet, V. T., \& Yeshaswini, T. (2011). Botox as an adjunct to orthognathic surgery for a case of severe vertical maxillary excess. Journal of maxillofacial and oral surgery, 10(3), 266-270.

Lemes, L. T. D. O., Laufer, E., Reckziegel, M., Montenegro, M. M., \& Kampits, C. (2018). Aumento de coroa clínica com a técnica flapless: relato de caso. Periodontia, 73-78.

Liébart, M. F., Fouque-Deruelle, C., Santini, A., Dillier, F. L., Monnet-Corti, V., Glise, J. M., \& Borghetti, A. (2004). Smile line and periodontium visibility. Periodont Pract today, 1,17-25.

Majzoub, Z. A., Romanos, A., \& Cordioli, G. (2014). Crown lengthening procedures: A literature review. In Seminars in Orthodontics, 20(3),188-207.

Chacón Martínez, H., Castro Govea, Y., Pérez Porras, S., Vázquez Costilla, O., González Cárdenas, H. R., \& Mendoza Adam, G. (2011). Simplificando el tratamiento quirúrgico de la sonrisa gingival. Cirugía Plástica Ibero-Latinoamericana, 37(1), 43-49.

Mazzuco, R., \& Hexsel, D. (2010). Gummy smile and botulinum toxin: a new approach based on the gingival exposure area. Journal of the American Academy of Dermatology, 63(6), 1042-1051.

Mishra, M. B., Khan, Z. Y., \& Mishra, S. (2011). Gingival overgrowth and drug association: a review. Indian journal of medical sciences, 65(2), 73-82.

Naldi, L. F., Adolfi, D., Adolfi, M. C., Mendonça, J. A. G., Leite, A. C., \& Oliveira, R. C. G. (2010). Use of polymethilmethacrylate for esthetic crown lengthening, associated with lip repositioning: an original method. TeamWork, 3(3), 26-35.

Nigam, P. K., \& Nigam, A. (2010). Botulinum Toxin. Indian J Dematol, 55(1), 8-14.

Oliveira, M. T., Molina, G. O., Furtado, A., Ghizoni, J. S., \& Pereira, J. R. (2013). Gummy smile: A contemporary and multidisciplinary overview. Dental Hypotheses, 4(2), 55.

Oliveira, P. S., Chiarelli, F., Rodrigues, J. A., Shibli, J. A., Zizzari, V. L., Piattelli, A., Iezzi, G., \& Perrotti, V. (2015). Aesthetic Surgical Crown Lengthening Procedure. Case Rep Dent, 437412.

Panossian, A. J., \& Block, M. S. (2010). Evaluation of the smile: facial and dental considerations. Journal of oral and maxillofacial surgery: official journal of the American Association of Oral and Maxillofacial Surgeons, 68(3), 547-554.

Pedron, I. G. (2016). Harmonização da Estética Dentogengivofacial. Clín. Int. J. Braz. Dent, 12(12),150-155.

Polo, M. (2008). Botulinum toxin type A (Botox) for the neuromuscular correction of excessive gingival display on smiling (gummy smile). American journal of orthodontics and dentofacial orthopedics, 133(2), 195-203.

Robbins, J. W. (1999). Differential diagnosis and treatment of excess gingival display. Practical periodontics and aesthetic dentistry: PPAD, 11(2), $265-272$.

Rossi, R., Brunelli, G., Piras, V., \& Pilloni, A. (2014). Altered passive eruption and familial trait: a preliminary investigation. International journal of dentistry, 874092 .

Sabri R. (2005). The eight components of a balanced smile. Journal of clinical orthodontics: JCO, 39(3), 155-154.

Seixas, M. R., Costa-Pinto, R. A., \& Araújo, T. M. D. (2011). Checklist of aesthetic features to consider in diagnosing and treating excessive gingival display (gummy smile). Dental Press Journal of Orthodontics, 16, 131-157.

Sevilha, F. M., Pessoa de Barros, T., Campolongo, G. D., \& Borelli, L.N. (2011). Toxina botulínica tipo A, uma alternativa para tratamentos odontológicos. Revista Braz J Periodontol, 21, 12-17.

Silberberg, N., Goldstein, M., \& Smidt, A. (2009). Excessive gingival display--etiology, diagnosis, and treatment modalities. Quintessence international (Berlin, Germany, 40(10), 809-818.

Silva, C. O., Ribeiro-Júnior, N. V., Campos, T. V., Rodrigues, J. G., \& Tatakis, D. N. (2013). Excessive gingival display: treatment by a modified lip repositioning technique. Journal of clinical periodontology, 40(3), 260-265.

Silva, H. F. V., Leite, R. B., Oliveira, M. S. G de., Leite, J. V. C., Felismino, C. M. de O., Cruz, M. E. de A., Santos, A., Gusmão, G.P., \& Lima, L. N. C. (2021). Avaliação de diferentes técnicas para correção do sorriso gengival: Revisão da literatura. Research, Society and Development, 10(5), e54510515092e54510515092.

Simon, Z., Rosenblatt, A., \& Dorfman, W. (2007). Eliminating a gummy smile with surgical lip repositioning. The journal of cosmetic dentistry, 23(1), 102109.

Suma, T., Shashikumar, H. C., Lokesh, N. K., Siddarth, A., \& Shwetha, G. S. (2014). Orthodontic surgical treatment of gummy smile with vertical maxillary excess. IOSR Journal of Dental and Medical Sciences, 13(10), 68-74.

Torres, É. M. D., Valladares-Neto, J., Bernades, K. D. O., Naldi, L. F., Torres, H. M. D., Carvalho, A. L., \& Estrela, C. (2020). Facial profile changes due to bone cement graft to manage the hyperactive muscles of the gingival smile. Dental Press Journal of Orthodontics, 25, 44-51.

Van der Geld, P., Oosterveld, P., Schols, J., \& Kuijpers-Jagtman, A. M. (2011). Smile line assessment comparing quantitative measurement and visual estimation. American journal of orthodontics and dentofacial orthopedics: official publication of the American Association of Orthodontists, its constituent societies, and the American Board of Orthodontics, 139(2), 174-180. 